УДК $801.561 .1(802.0)$

DOI: $10.21779 / 2542-0313-2016-31-3-34-40$

\title{
Т.И. Аиурбекова
}

\section{Воздействующий потенциал актуального членения в общественно-политическом тексте}

Дагестанский государственный университет; Россия, 367001, 2. Махачкала, ул. М. Гаджиева,43a; tiashu@mail.ru

В статье на материале фрагмента из текста вступительной речи Генерального секретаря $\mathrm{OOH}$ на 69-й сессии Генеральной ассамблеи ООН и его переводов на русский язык рассматривается один из малоизученных аспектов теории актуального членения предложения, а именно его роль в создании воздействующего эффекта письменного текста. Рассматриваемый фрагмент посвящен проблеме нарушения прав человека и законности. Сравниваются два перевода - официальный и предложенный автором статьи. В официальном переводе в основном сохраняются синтаксическая структура и порядок слов оригинального текста, что, в силу различия строя английского и русского языков, приводит к определенному искажению тема-рематической структуры оригинала и ослаблению его воздействующего потенциала. Текст перевода воспринимается как напоминание о нарушениях прав человека в ряде стран и оценка этого явления. Во втором переводе производятся синтаксические преобразования, в результате которых текст выстраивается по модели рематической прогрессии с локативно-оценочной доминантой и внеположенной темой, задаваемой в опорном предложении. По мнению автора, в этом случае смыслом фрагмента становится демонстрация масштаба нарушения прав человека и законности в современном мире и побуждение аудитории к действию через прогнозируемое разделение ясно выраженной оценки. В статье подчеркивается необходимость более углубленного изучения проблематики актуального членения при подготовке переводчиков.

Ключевые слова: актуальное членение предложения, тема, рема, эпидейктическая речь, воздействие, перевод.

UDC 801.561.1 (802.0)

DOI: $10.21779 / 2542-0313-2016-31-3-34-40$

\section{The implications behind functional sentence perspective in socio-political discourse}

\section{T.I. Ashurbekova}

Dagestan State University; M. Gajiev st., 43a, 367001 Makhachkala, Russian Federation; tiashu@mail.ru

The paper is an examination of an excerpt from Ban Ki-moon's inaugural speech at $69^{\text {th }} \mathrm{UN}$ General Assembly and its two Russian translations from the point of view of implications behind their functional sentence perspectives (FSP). The speech is devoted to the human rights and the rule of law violations in the contemporary world. The official translation and the one made by the author are compared. The authorized translator preserves the syntactic structure and the word order of the original, which causes some distortion of the original theme-rheme structure due to the differences in the systems of the two languages. According to the author, this weakens Ban Ki-moon's message which, in this case, is perceived as a mere reminder of human rights violations in a number of countries and their evaluation. In the second translation, due to syntactic transformations, the theme-rheme pattern is one

34 Вестник Дагестанского государственного университета.

Серия 2. Гуманитарные науки. 2016. Том. 31. Вып. 3 
of rhematic progression with a locative semantic dominant, which implies that Ban Ki-moon aims at demonstrating the scope of human rights violations. The author also considers that the excerpt contains another semantic dominant constituted by the numerous emotive-evaluative words. The effect is that of evoking readers' empathy and urging them to contribute to the solution of the human rights problem. The importance of considering FSP implications for the message is emphasized from the standpoint of translators training.

Ключевые слова: functional sentence perspective, theme, rheme, epidemic speech, effect, translation.

Феномен актуального членения предложения (в иной терминологии - функциональной перспективы предложения, ФПП) в силу множественности, многоаспектности своей природы вот уже более ста лет привлекает внимание многочисленных исследователей [1]. Многие положения теории АЧ продолжают оставаться дискуссионными. В частности, не существует единства в понимании соотношения АЧ, с одной стороны, и информационной, семантической и линейной структуры предложения - с другой. Как следствие, отсутствует единый подход к определению понятий темы и ремы [2]. Малоизученным остается и вклад АЧ в воздействующий потенциал текста. В то же время рассмотрение АЧ с точки зрения воздействия на реципиента устной и письменной речи представляет значительный практический и теоретический интерес.

Работы, посвященные аспектам воздействующего потенциала АЧ, о котором часто говорят как об экспрессивности, немногочисленны. Первой известной нам попыткой рассмотрения текста, затрагивающего этот вопрос, стала работа Б.А. Ильиша. На примере анализа начала первой главы романа Э. Хемингуэя «По ком звонит колокол» ему удалось показать, что выбранное автором актуальное членение заставляет читателя отождествлять себя с героем, смотреть на окружающее его глазами, что придает стилю Хемингуэя остроту и выразительность [3].

Особого внимания заслуживают исследования видного представителя Пражской лингвистической школы, создателя стройной теории функциональной перспективы предложения Яна Фирбаса. Для демонстрации вклада ФПП в экспрессивность художественного текста он проанализировал переводы на английский, немецкий, французский и голландский языки начала романа Бориса Пастернака «Доктор Живаго» и показал, что даже незначительные отклонения от оригинала в коммуникативной нагрузке (в его терминологии - коммуникативном динамизме) элементов в переводном тексте влияют на расстановку смысловых акцентов при восприятии текста читателем и в определенной степени искажают интенцию автора произведения [4]. На материале переводов английских художественных текстов на венгерский язык исследование с аналогичными выводами выполнил Янош Надь [5].

В исследовании А.С. Коломийцевой на материале полипредикативных предложений-абзацев из художественных произведений показано, что АЧ вносит вклад в достижение эффекта эмотивности [6]. В работе [7] исследуется АЧ несобственно-прямой речи в прозе Д. Джойса и делается вывод о том, что посредством актуального членения передается имплицитная информация о внутреннем состоянии, нравственных качествах, духовных приоритетах героев художественного произведения. Неявная передача такой информации приводит к тому, что внимательный читатель сам делает соответствующие выводы, чем достигается особая убедительность повествования в форме несобственно-прямой речи. 
Вновь обратиться к рассмотрению АЧ с точки зрения его воздействия на читателя нас побудил опыт преподавания курса общественно-политического перевода для студентов магистратуры. В частности, обнаружилось, что приводимые в учебниках по переводу объяснения сути АЧ и его роли в построении текста перевода оказываются недостаточными. Студентам требуются дополнительные, более весомые аргументы в пользу того, что сохранение в переводе актуального членения исходного текста не просто делает перевод более удобочитаемым, но и способствует решению другой важной задачи, которую В.В. Сдобников сформулировал следующим образом: «Перевод представляет собой лингвоэтническую ретрансляцию, предполагающую преобразования, связанные с различиями в языках и культурах. Общение через лингвоэтнический барьер имеет целью оказать определенное воздействие на получателя перевода» [8, с. 12-13].

В этой связи представляется целесообразным обратиться к речевым жанрам, одной из основных целеустановок которых является оказание воздействия, и рассмотреть их актуальное членение. Сделаем это на примере текста вступительной речи (ВР) на крупном общественно-политическом мероприятии. Как содержательное произведение эпидейктического жанра, ВР имеет своей целью раскрыть смысл мероприятия, сформулировать проблемы, представить идеи, подчеркнуть значительность деятельности каждого участника мероприятия и призвать всех к единению. Основным содержанием такой речи обычно являются иллюстрации, сравнения и оценки [9].

Вступительная речь на общественно-политическом мероприятии - пример эмотивной коммуникации, которая, по определению Т.В. Лариной, является сознательной, контролируемой демонстрацией эмоций, ориентированной на объект и используемой в целях воздействия на окружающих с тем, чтобы повлиять на восприятие ими ситуации и на ее понимание [10, с. 37]. Особенностью эпидейктической речи является то, что она должна вызывать ответные чувства, причем, если в речи осуждаются какие-либо явления, то ответным чувством должно быть не уныние и безнадежность, а желание исправить недостатки.

Обратимся к анализу коммуникативной структуры отрывка из ВР Генерального секретаря ООН Пан Ги Муна на 69-й сессии Генеральной Ассамблеи ООН 24 сентября 2014 года:

(1) It has been a terrible year for the principles enshrined in the United Nations Charter. (2) From barrel bombs to beheadings, from the deliberate starvation of civilians to the assault on hospitals, UN shelters and aid convoys, human rights and the rule of law are under attack. (3) After the latest tragedy in Gaza, Palestinians and Israelis seem more polarized than ever. ... (4) The situation in and around Ukraine remains volatile. (5) In South Sudan, a struggle for political power has killed thousands of people and exposed millions to the threat of famine. (6) The Central African Republic is fractured and traumatized. (7) Mali and Sahel continue to suffer from insurgency, terrorism, the illicit drug trade and organized crime. (8) In Somalia, a coalition of African States confronts the terrorist group Al-Shabab. (9) In Nigeria, Boko Haram's murderous onslaught gains strength, with shocking impacts on women and girls. (10) In Iraq and Syria, we see new depths of barbarity with each passing day, and devastating spill-over effects across the region [11] (зесь и далее нумерация предложений и жирный шрифт наши. - T.A.).

Приведем официальный перевод данного фрагмента:

(1) Прошедший год был весьма плохим с точки зрения соблюдения принциипов, воплощенных в Уставе Организачии Объединенных Начий. (2) Объектом для посягательств становятся права человека и верховенство права: речь идет о применении бочковых бомб и обезглавливании людей, преднамеренном обречении на голод граждан-

\begin{tabular}{c}
\hline 6 Вестник Дагестанского государственного университета. \\
Серия 2. Гуманитарные науки. 2016. Том. 31. Вып. 3
\end{tabular} 
ского населения и нападениях на больниць, приюты Организации Объединенных Наџий и автоколонны с гуманитарной помощью. (3) После последней трагедии в Газе палестинцы и израильтяне разобщены как никогда ранее. ... (4) Ситуация в Украине и вокруг нее остается нестабильной. (5) В Южном Судане в результате борьбы за политическую власть погибли тысячи людей, а миллионам угрожает голод. (6) Центральноафриканская Республика расколота и находится в тяжелой ситуации. (7) Мали и Сахель по-прежнему страдают от мятежей, терроризма, незаконной торговли наркотиками и организованной преступности. (8) В Сомали коалиция африканских государств ведет борьбу с террористической группой «Аш-Шабаб». (9) В Нигерии смертоносный натиск со стороны «Боко-Харам» становится все более ожесточенным, приводя к ужасаюшим последствиям для женшин и девочек. (10) В Ираке и Сирии мы ежедневно сталкиваемся с новыми проявлениями варварства, которые оказывают разрушительное воздействие на весь регион» [12].

Отметим вначале, что вслед за основателем теории АЧ В. Матезиусом и в соответствии с традициями Пражской школы основным фактором, влияющим на коммуникативный статус элемента, мы будем считать степень его контекстуальной зависимости, его выводимость (retrievability) из ближайшего предшествующего контекста. Релевантными для исследования являются также идеи коммуникативного структурирования текста по принципу тематической и рематической прогрессии $[13,14]$. В теоретическую базу работы также входят исследования порядка слов в языках с синтетическим и аналитическим строем, в частности положение о том, что для русского языка «влияние предшествующего текста на порядок слов в данной фразе - фактор очень сильный и даже, возможно, решающий»; в английском же языке порядок слов определяется структурными соображениями и является достаточно жестким: одной синтаксической связи обычно соответствует одно допустимое расположение элементов [15, с. 269]. Как следствие, для русского языка, а также других языков с синтетическим строем, например чешского, типичным, немаркированным является начальное расположение темы, в то время как рема тяготеет к концу предложения. В английском языке рема может занимать как конечную, так и начальную позицию в предложении. Более того, в английском языке по принципу развертывания мысли от ремы к теме могут строиться не только отдельные высказывания, но и целые абзацы.

Жирным шрифтом в оригинале и переводе нами выделены словосочетания, на которые будет обращено особое внимание в ходе анализа актуального членения приведенного фрагмента ВР. Как мы видим, переводчик, за исключением предложения (2), сохранил порядок слов и синтаксическую структуру оригинала. Однако сохранилось ли при этом его актуальное членение, его тема-рематическая структура? О том, насколько это важно, пишет Ян Фирбас, который полагает, что функциональная перспектива письменного предложения передает и раскрывает коммуникативную цель автора. Вполне оправданно поэтому требовать от переводчика правильного понимания функциональной перспективы оригинала и нахождения средств ее воссоздания в переводе. Для этого может потребоваться преобразование грамматических структур оригинала. Вопрос о том, насколько терпима неадекватная передача оригинала, остается открытым: текст может хорошо читаться, даже если перевод выполнен неправильно. В то же время следует помнить, что неверная передача в переводе функциональной перспективы оригинала может привести к тому, что существенная информация будет представлена в ином свете, а важные аспекты сообщения будут утрачены для читателя [4, c. 140]. Забегая вперед, отметим здесь, что одним из этих важных аспектов может оказаться и воздействующий потенциал сообщения. 
В плане содержания приведенный фрагмент речи Пан Ги Муна является раскрытием темы «нарушения прав человека и законности в современном мире», вербальной манифестацией которой является фраза human rights and the rule of law are under attack. В предложении (2) она является ремой. В последующих предложениях называются страны и кратко описывается суть проблем, с которыми они столкнулись. С этой точки зрения несколько выделяется предложение (3), где страны обозначены через наименование их народов (Palestinians and Israelis), поскольку начальная позиция в предложении занята «конкурирующим» обстоятельством времени. Все названия стран являются контекстуально независимыми элементами, однако переводчик сохраняет их начальную позицию, которая в русском языке обычно отводится теме (мы не рассматриваем здесь случаи с маркированным словопорядком), следовательно, их коммуникативный статус может быть расценен как тема-новое. Коммуникативное структурирование перевода осуществляется по модели рематической прогрессии с семантической доминантой «нарушения прав человека и законности», введенной в предложении (2) и конкретизируемой в ремах предложений (3)-(10).

Пан Ги Мун обращается к конструктивной аудитории, прекрасно осведомленной о событиях, о которых идет речь в данном фрагменте ВР, следовательно, коммуникативной целью Генерального секретаря ООН вряд ли является сообщение новой информации. В соответствии с тема-рематической организацией перевода, это, скорее, напоминание о том, что существует еще немало стран с неблагополучной ситуацией, и оценка происходящих в них событий.

Рассмотрим иной вариант перевода фрагмента речи Пан Ги Муна:

(1) С точки зрения соблюдения принципов, воплощенных в Уставе Организачии Объединенных Начий, события этого года вызывают ужас. (2) Применение бочковых бомб, обезглавливание людей, преднамеренное обречение на голод гражданского населения, нападения на больницы, приюты ООН и гуманитарные конвои - все это грубейшие нарушения прав человека и принципа верховенства закона. (3) В результате последней трагедии в Газе как никогда ранее разобщены народы Палестины и Израиля. ... (4) Нестабильной остается ситуация в Украине и на сопредельных территориях. (5) В ходе борьбы за политическую власть погибли тысячи людей, а миллионам угрожает голод в Южннм Судане. (6) Расколота и переживает тяжелый кризис Центральноафриканская Республика. (7) По-прежнему страдают от мятежей, терроризма, незаконной торговли наркотиками и организованной преступности Мали и Сахель. (8) С террористической группировкой «Аш-Шабаб» ведет борьбу коалиция африканских государств в Сомали. (9) Все более ожесточенным и губительным для женщин и девочек становится смертоносный натиск "Боко-Харам» в Нигерии. (10) С ежедневныли новыми проявлениями варварства, оказывающими разрушительное воздействие на весь регион, сталкиваются Ирак и Сирия.

Синтаксические преобразования, выполненные при перемещении элементов с локативной семантикой в конец предложений, и другие сопутствующие изменения в порядке слов привели к изменению коммуникативной структуры предложений и фрагмента в целом. Во втором варианте перевода контекстуально независимые наименования стран входят в состав ремы и являются ее ядром. Более того, при инвертированном порядке слов в предложениях (3)-(10) не осталось элементов, могущих претендовать на роль темы. В этой ситуации функциональную перспективу данных предложений целесообразно определить на фоне всего фрагмента: если рассматривать предложение (2) как часть текста, в которой задается тема, то предложения (3)-(10) можно трактовать как полностью рематические, т. е. как предложения с внеположенной темой. В работе [16], выполненной на материале газетных текстов, предложения, устанавливающие те-

38 Вестник Дагестанского государственного университета.

Серия 2. Гуманитарные науки. 2016. Том. 31. Вып. 3 
му, называются опорными: они заключают в себе аналитическое утверждение, выражающее взгляд на что-либо, мнение о чем-либо. С другой стороны, сообщения о фактах, свидетельствующих о правомерности такого утверждения, называются зависимыми, «несущими рему».

Коммуникативную структуру рассматриваемого фрагмента, таким образом, можно описать как рематическую прогрессию с локативной семантической доминантой. Однако было бы неправильно проигнорировать остальную часть рематического содержания, в частности, многочисленные эмоционально-оценочные лексические единицы и их сочетания, такие как polarized, volatile, killed, threat of famine, fractured and traumatized, insurgency, terrorism, illicit drug trade, organized crime, terrorist group, murderous onslaught, shocking impacts, barbarity, devastating и другие, которые, на наш взгляд, образуют параллельную смысловую доминанту оценки.

В приведенной интерпретации оригинала смыслом анализируемого фрагмента ВР становится демонстрация масштаба нарушений прав человека и законности в современном мире, своего рода представление карты горячих точек, а также побуждение читателя к действию через прогнозируемое разделение ясно выраженной оценки сложившейся ситуации.

Разумеется, в данной статье актуальное членение рассматриваемого фрагмента вступительной речи представлено упрощенно, с акцентом на моменты, призванные подкрепить мысль автора о том, что оно является важным инструментом в арсенале средств речевого воздействия.

Возвращаясь к вопросам обучения переводу, процитируем Кристофера Хопкинса: «Переводчики часто оказываются в ловушке: в поисках полной синтаксической эквивалентности они забывают о том, что синтаксические структуры труднее всего поддаются преобразованиям при переводе» (цит. по [17, с. 11]). Между тем, как мы попытались продемонстрировать, такие преобразования необходимы для передачи актуального членения оригинала, могущего заключать в себе значительный воздействующий потенциал.

\section{Литература}

1. Иванов Н.В. Актуальное членение предложения: на пути к новой парадигме теории // Проблемы и перспективы развития лингвистики, межкультурной коммуникации и лингводидактики. - М.: Резонанс, 2009. - Вып. 3.

2. Ащурбекова Т.И. Проблема определения темы и ремы в теории актуального членения предложения // Вестник ДГУ. - 2013. - Вып. 3.

3. Ильиш Б.А. Об актуальном членении предложения // Уч. зап. Ленингр. гос. пед. ин-та. - 1969. - Т. 352.

4. Firbas $J$. Translating the introductory paragraph of Boris Pasternak's Doctor Zhivago. A case study in functional sentence perspective // Andermann G., Rogers M. (eds.) Word, Text, Translation: Liber Amicorum for Peter Newmark. - Clevedon: Multilingual Matters Ltd. - 1999. - P. 119-129.

5. Nagy J. The (relative) balance of communicative dynamism in translation / Summary of the doctoral thesis. - Budapest, 2015. - [Электронный pecypc]. - URL: http://doktori.btk.elte.hu/lingv/nagyjanos/thesis.pdf.

6. Коломийцева A.C. Коммуникативно-прагматический потенциал полипредикативных сложных предложений-абзацев как единиц текста // Культурная жизнь Юга России. - 2011. - № 1 (39). 
7. Ashurbekova T.I. The contribution of functional sentence perspective to character's image creation in free indirect discourse // Studii si Cercetari Filologice. Seria Limbi Străine Aplicate. - Piteşti: Piteşti University Press, 2012. - № 11.

8. Сдобников B.B. Коммуникативная ситуация как основа выбора стратегии перевода: автореф. дис. ... докт. филол. наук. - М., 2015.

9. Анисимова T.В., Гимпельсон Е.Г. Современная деловая риторика. - М.: МОДЭК, 2004.

10. Ларина T.B. Выражение эмоций в английской и русской коммуникативных культурах // Язык и эмоции: личностные смыслы и доминанты в речевой деятельности: сб. науч. трудов. - Волгоград: Из-во ЦОП «Центр», 2004.

11. Inaugural Speech by Ban Ki-moon at $69^{\text {th }}$ UN General Assembly. September 24, 2014. - [Электронный pecypc]. - URL: http://www.voltairenet.org/article185434.html.

12. Обращение к Генеральной Ассамблее «От нестабильности к миру». Нью-Йорк. 24 сентября. 2014 год. - [Электронный ресурс]. - URL: http://www.un.org/en/ga/69/meetings/gadebate/pdf/BK_ru.pdf.

13. Daneš $F$. Functional sentence perspective and the organization of the text // Papers on functional sentence perspective. - Prague, 1974. - P. 106-128. 1982.

14. Золотова Г.А. Коммуникативные аспекты русского синтаксиса. - М.: Наука,

15. Мельчук И.А. Опыт теории лингвистических моделей «Смысл - текст». - М.: Школа «Языки русской культуры». - 1999.

16. Давыдова А.Р. Тема-рематическая организация текста газетных сообщений // Известия РГПУ им. А.И. Герцена. - 2007. - № 40.

17. Minarčiková H. FSP in Translation: a Research-based Study of FSP Deficiencies in Student Translations from English to Czech / Master's Diploma Thesis. - Masaryk University, 2012. - 2 [Электронный pecypc]. - URL: https://is.muni.cz/th/178822/ff_m/Master_s_Diploma_Thesis_Minarcikova.txt.

Поступила в редакиию 14 октября 2016 г.

Received 14 October, 2016 